\title{
A COMUNICAÇÃO SIMBOLICA DO ESTILO ART NOUVEAU COMO REFERENCIAL PARA A CRIAÇÃO DE JOIAS
}

\author{
Fabiane Lima Ledel ${ }^{\mathrm{i}}$
}

\section{RESUMO}

O presente trabalho busca inspiração nos elementos estruturais e decorativos utilizados no Estilo Art Nouveau, em seus aspectos artísticos e simbólicos, para criar jóias que sejam de uso universal e inserido num mercado competitivo. A partir de um referencial bibliográfico busca-se compreender a significação do referenciado estilo e traduzi-lo no produto - a jóia, partilhando valores culturais, sociais e mercadológicos.

PALAVRAS CHAVE: comunicação, design, jóia, consumidor

\section{RESUMEN}

Este trabajo busca la inspiración en los elementos decorativos y estructurales utilizados en estilo Art Nouveau, en los aspectos artísticos y simbólicos, para crear joyas que son de uso universal y alojados en un mercado competitivo. Las referencias bibliográficas de una búsqueda para entender el significado del estilo de referencia y traducirlo en productos joyas, el intercambio de valores culturales, sociales y de mercado.

PALABRAS CLAVE: comunicación; design, joya, consumidor

\begin{abstract}
This paper seeks inspiration in the decorative and structural elements used in Art Nouveau style, in artistic and symbolic aspects, to create jewelry that are of universal use and housed in a competitive market. The bibliographic references from a search to understand the meaning of the referenced style and translate it into products - jewelry, sharing cultural values , social and market.
\end{abstract}

KEY WORDS: communication; design; jewelry; consumer

\section{Introdução}

Este estudo parte da análise da comunicação simbólica estilo Art Nouveau para referenciar a elaboração do projeto de uma jóia. O Art Nouveau surgiu no final do século XIX, influenciado pelos ideais do movimento "Art and Crafts", trouxe mudanças radicais para o campo artístico e cultural.

Para os precursores desse estilo, diferente do trabalho artesanal, a máquina não proporcionava a liberdade de criação e da forma. Motivados pelo espírito de renovação, os artistas e designers, acreditavam que para se aproximar de uma arte moderna era necessário romper com estilos clássicos ultrapassados. Essas ideias tornaram-se uma meta, que foi seguida por diversos artistas em várias partes do mundo. Apesar do curto período de duração, 
o Art Nouveau difundiu-se pela Europa e América, recebendo diversos títulos e criando características próprias onde se manifestava.

O tema do estilo Art Nouveau, foi o universo natural onde formas fitomórficas e biomórficas inspiraram artistas na criação de móveis, jóias, estruturas, decoração de interiores, pintura, escultura, artes gráficas, entre outros. As linhas delicadas, ondulantes, estilizadas atingiram rapidamente um patamar internacional, em diversos setores das artes decorativas e aplicadas, mas, foi na arquitetura que obteve sua expressão máxima. $\mathrm{O}$ privilégio da forma, o desenho e o emprego de novos materiais como vidro e o ferro, contribuíram para a consolidação da arte moderna e do design, redefinindo conceitos e novas possibilidades de criação.

\section{Sobre comunicação, jóias e design}

A indústria joalheira brasileira, com o apoio o Instituto Brasileiro de Gemas e Metais Preciosos (IBGM), a partir da década de noventa abriu portas para a criatividade, a originalidade e a liberdade de criação, o que tornou possível a exploração de materiais típicos do Brasil, valorizando as gemas e metais preciosos, além da grande diversidade de matériaprima, o que podemos observar nas jóias com design inovador e criativo. Em Löbach (2000, p. 12), “o design é o emprego econômico de meios estéticos no desenvolvimento de produtos, de modo que estes atraiam a atenção dos possíveis compradores, ao mesmo tempo em que otimizem valores de uso dos produtos comercializados".

O design inovador e a busca por um diferencial na jóia, com a mistura de materiais inusitados, tornaram o mercado capaz de concorrer com produtos importados, servindo de inspiração para designers e estilistas no mundo. A literatura nos mostra que, o papel do design surge quando a forma de confeccionar jóias deixa de ser realizada apenas pelo artesão. Com a era tecnológica e digital, surgiu a necessidade de capacitar um profissional designado ao planejamento e criação de jóias, pensando nos materiais e processos que implicarão na sua materialização.

Neste contexto encontra-se a moda envolvida com a joalheria. Este setor vem investindo em coleções sazonais, aliando ao vestuário, com coleções inovadoras que acompanham o ritmo das tendências. A aproximação da joalheria com o universo da moda permite que o mercado cresça, explore temas, formas, cores, abrindo um leque de opções para o setor.

Para o IBGM (Instituto Nacional de Metais e Pedras Preciosas 2011), 
as jóias caminham sem censura, por trilhas até então pouco exploradas na joalheria. Materiais inusitados são vistos a todo o momento nas coleções brasileiras, assim como formas surpreendentes. Tudo isso com uma linguagem contemporânea, atualizada, que encontra forte identificação com o desejo do consumidor moderno, seja ele brasileiro, americano, europeu ou asiático.

Pesquisas mostram que os bens de consumo de alto valor tecnológico, como, celulares, câmeras digitais, entre outros, são os maiores concorrentes do mercado joalheiro no mundo. A partir de pesquisas, foi constato que exportações e vendas no setor da indústria de folheados e bijuterias, sofreu grande acréscimo. Esses produtos competem com produtos de qualidade, em razão do design diferenciado, a mistura de materiais e preços acessíveis.

A julgar pelas inúmeras feiras nacionais, internacionais, pela mídia e publicidade, pode-se afirmar que as principais tendências de mercado joalheiro no Brasil e no mundo são: o crescente volume de jóias folheadas e bijuterias; grande utilização de gemas e lapidações diferenciadas; a concorrência de jóias com produtos de alta tecnologia principalmente eletrônicos, e ainda a preocupação de designers e empresas com a questão ecológica, no que diz respeito à escolha e utilização adequada de materiais na fabricação de projetos sustentáveis.

A alta joalheria requer habilidades artesanais, em razão dos detalhes e do uso de materiais e metais preciosos. Para atingir a perfeição, é essencial o conhecimento e prática para criar peças de qualidade. No Brasil, grande quantidade da produção joalheira vale-se de processos artesanais, onde o mais comum é a fundição.

No mercado comercial as joalherias consagradas aliam o design a elementos da moda e vestuário, utilizando-os como fonte de inspiração para suas coleções. Assim, como a moda transforma-se a cada estação, o setor joalheiro foca nesse caminho que está em constante mutação e que proporciona movimentação para o setor. As jóias comerciais passam por procedimentos industriais, onde são produzidas em grande escala e há pouco tempo, eram confeccionadas apenas pelo processo manual, pois, a máquina limitava a criatividade. Com a evolução tecnológica, as indústrias encontram-se aptas a desenvolver peças que antes seriam impossíveis de ser atingidas pelo processo artesanal, além, de agilizar o processo e reduzir custos. Pedrosa apud Lisbôa (2011) clarifica que a joalheria mundial está voltada para o design criativo, identificável voltado para um mercado crescente e um consumidor ansioso por inovações. 
Com a era tecnológica surge a cultura de massa e a indústria de consumo. O marketing e a publicidade transferem aos consumidores signos e símbolos, que são transformados em sensação de bem-estar, auto realização, satisfação e status social. Assim, o homem cria estratégias de comunicação para que o produto tenha aceitação no mercado.

O consumo é manipulado pelas grandes empresas e organizações que detém poder sobre a sociedade menos desenvolvida. Deste modo influi no que deve ser usado, o que é belo e bom, colocando à frente dos consumidores inúmeras possibilidade de escolha.

Paradoxalmente, vive-se na era moderna uma cultura que, apesar de nascer ou frutificar nos meios de comunicação de massa, ainda oscila entre um desenvolvimento genuíno e a cultura da indústria capitalista, que evidencia a expansão da cultura burguesa, atingindo o imenso universo de consumo. (HILL, 2006 p.39)

O que sustenta o capitalismo e a indústria de consumo são as necessidades das pessoas, que são, em grande parte, geradas pela mídia e pelos meios de comunicação. $\mathrm{O}$ marketing é o responsável por sensibilizar o consumidor, criando um ambiente satisfatório, gerando desejo de consumo. Assim, cria-se um clico de consumismo, onde as pessoas trabalham para poder consumir.

Gastar, fruir a vida e ceder aos próprios impulsos são as três ordens essenciais desta era mecanizada, que vão ser mascaradas pelos artifícios das empresas capitalistas. Está-se num círculo vicioso: deve-se consumir por que se produz, e deve-se produzir por que se fabricam "necessidades". (HILL, 2006, p.44 ).

Constata-se na sociedade capitalista que, a grande concorrência leva as empresas criarem novos produtos a todo o momento, motivando os indivíduos a possuir o que está à frente.

\section{Aspectos simbólicos no design de jóias}

Desde os primórdios da humanidade, surgiu a necessidade de criar ornamentos. "O estudo da história da ornamentação humana constitui um valioso instrumento para reconstruir a própria história do homem através dos seus costumes, das tradições, das crenças, dos seus conhecimentos tecnológicos e dos seus gostos estéticos”. (CODINA, 2000, p. 8)

Ao longo da evolução do homem, os adornos são utilizados, seja como amuleto, moeda ou distinção social. Para o Duarte (2006, p.15), “as jóias são documentos eternos". Contam a história de povos que antecedem a escrita, pois sintetizam o contexto 
sócio/econômico e cultural de uma época, permitindo uma reflexão do homem contemporâneo.

A literatura revisada nos induz a pensar que as primeiras relações entre o homem e adorno iniciam no Paleolítico, no período da Pedra Lascada, onde não existia uma preocupação com a estética dos adornos. Esses eram confeccionados com materiais diversos, encontrados na natureza, e alguns decorriam da caça. Somente no período Neolítico, final da época glacial (8000 a.C.), como a evolução dos grupos e de suas culturas é que aparecem os primeiros indícios de uma sociedade. Surgem a agricultura, o comércio, as classes sociais e os ofícios, que estabelecem as bases técnicas, sociais e econômicas. Além disso, aparecem os cultos e crenças no sobrenatural, bem como o uso de materiais preciosos para a criação de adornos.

A jóia enquanto arte começou a desenvolver-se em meados dos anos 50, como uma via de expressão pessoal tanto para o criador como para o portador da jóia, retomando o espírito renovador de princípios do século, e à qual teriam acesso apenas umas minorias. (CODINA, 2000, p.10)

As joias representam aspirações e riquezas que adornavam o corpo desde os povos antigos. As técnicas descobertas abriram caminho para a consolidação da joalheria moderna e contemporânea que hoje é orientada pelos símbolos e culturas que decorrem do processo evolutivo do homem. A joalheria não se define, como antigamente, pelo tipo de metal com que se trabalha. Hoje em dia, não existe uniformidade de estilos, mas sim uma conjunção e uma pequena grande diversidade de materiais e conceitos. (CODINA, 2000, p.6)

Além de proporcionar funcionalidade, os objetos produzem sentimentos e emoções. Faz parte da natureza humana, procurarmos nos cercar de objetos que reflitam a nossa autoimagem onde todos compõe um mosaico que, juntos, constituem a nossa imagem visual que projetamos aos outros (BAXTER 1998, p. 189).

A essência da jóia remete aos símbolos e significados implícitos nos materiais, e conceitos, que remetem à cultura e à identidade, capazes de transmitir mensagens por meio do design.

Santaella (2003, p.13) afirma que, "a semiótica é a ciência que tem por objeto de investigação todas as linguagens possíveis, ou seja, que tem por objetivo o exame dos modos de constituição de todo e qualquer fenômeno como fenômeno de produção de significado e de sentido". Para a empresa Tiffany, a mulher que receber um anel da Tiffany sempre saberá que 
sua jóia é superior. Essa mensagem torna o produto alvo de desejo de consumo, suprindo as necessidades e expectativas criadas pelo indivíduo.

\section{Sobre o movimento estilístico Art Nouveau}

No final do século XIX, o Art Nouveau, trouxe mudanças significativas para o campo cultural e artístico. A expressão Art Nouveau surgiu do nome dado por Samuel Bing a sua galeria que, pretendia que o local transmitisse ideias de inovação e se aliasse as tendências de arte moderna. Nesta galeria, o propósito era deixar claro que ali só seriam expostos produtos inovadores como, móveis, jóias, objetos de decoração, entre outros. Bing contou com a contribuição de vários artistas para realizar os projetos da galeria, que colaboraram para o sucesso do lugar, gerando curiosidade dos parisienses. Exuberante e expressivo são termos que descrevem com clareza o estilo que apesar de seu curto período, marcou a história. Esse movimento disseminou-se rapidamente pela Europa e América, recebendo diversas denominações como, Modern Style, Modernismo, jugendstil, Sezession, Liberty, entre outros.

Ao longo da magnitude de significados, o Art Nouveau atingiu patamar internacional, manifestando características distintas, em vários campos artísticos como, escultura, pintura, arte gráfica, arquitetura, design de interiores, móveis, jóias entre outros. Em oposição ao ecletismo e a era industrial, o Art Nouveau surgiu, com a intenção de renovar a arte, privilegiando a forma, a liberdade de criação e a qualidade dos produtos através do trabalho artesanal. De acordo com Codina (2000, p.9), pela primeira vez valorizou-se na joalheria, mais a criatividade e a imaginação do que os materiais utilizados.

Para os artistas, a arte seria um veículo para a propagação de novas ideias, abrindo os horizontes para a arte moderna. Segundo a revista L'Art Moderne, “A Art Nouveau, deve lutar contra o feio e o pretensioso nas coisas que nos rodeiam e substituí-lo por um gosto perfeito, pelo encanto e beleza simples, inclusive nos utensílios mais insignificantes" (HEYL 2009, p.49).

A favor de formas suaves, motivos florais delicados e linhas sinuosas, o tema central do Art Nouveau foi à renovação no campo das artes decorativas e aplicadas. A natureza proporcionava inspiração aos que estavam cansados dos elementos tradicionais, e, recorriam para o bom gosto, através da representação estilizada de formas femininas e elementos da natureza. Cada artista tinha uma percepção diferente, desenvolvendo características singulares visíveis em cada obra.

Em relação ao movimento Art Nouveau, Moraes (1999, p.23) comenta, 
tal movimento procurava também algo que representasse o desenvolvimento da indústria de então, que já era mais capacitada e que necessitava de inovações para atender os anseios da burguesia da época, que aspirava por mais novidades dos produtos de arte aplicada. Mas a verdadeira intenção do Art Nouveau era, unir a originalidade à utilidade, em uma relação mútua e produtiva.

Ainda, para os autores supracitados embora o movimento pregasse um apelo à arte moderna, muitos artistas buscavam inspiração na arte medieval, técnicas célticas e na decoração da cultura japonesa, destacando-se, por tornar esses elementos originais e modernos. Esse estilo tornou-se tendência, e, criou relações com a música, poesia, teatro, atraindo vários admiradores. Portanto, a visão futurista dos artistas do fim do século XIX, a valorização da forma aliada a novas tecnologias e o emprego de novos materiais, conduziu a humanidade para a consolidação da arte moderna.

\section{Conclusão}

Os processos que envolvem um projeto de design consideram a comunicação, o simbolismo, os materiais, as tecnologias, questões mercadológicas, sociais e culturais e contribuem para o sucesso do produto. Com o objetivo de atender as expectativas do consumidor moderno, buscando satisfazer suas necessidades e expectativas e o mercado joalheiro em expansão.

É possível buscar um conceito para a criação de jóias inspiradas em elementos que caracterizam a comunicação simbólica do Estilo Artístico Art Nouveau, considerando a matéria prima brasileira (gemas e metais preciosos) para ser usada por diversas etnias em diferentes mercados mundializados. Ainda, com o mercado globalizado pelos meios de comunicação tem-se na publicidade e no apelo visual do produto um forte aliado para a difusão e comercialização do produto

\section{Referências}

BARILLI, Renato. Os estilos na arte art nouveau. São Paulo: Martins Fontes, 1991.

BAXTER, Mike. Projeto de produto: guia prático para o design de novos produtos.

2. ed. São Paulo:Edgard Blücher, 1998.

\section{CATÁlogo OFICIAL Tiffany \& Co.}

CODINA, Carles. A joalharia. Lisboa, PT: Estampa 2000.

HEYL VON, Anke. A arte nova. Ullmann-publishing, 2009.

HILL, Telenia. Homem, cultura e sociedade. Rio de Janeiro: Lucerna, 2006. 
IBGM, Instituto Brasileiro de Gemas e Metais Preciosos. Preview design de jóias e bijuterias. SEBRAE, ApexBrasil, 2011.

LISBÔA, Maria da Graça Portela. Design de jóias: do projeto ao produto: Coleção Gauchidade. Santa Maria, RS: EdUNIFRA, 2011.

LÖBACH, Bernd. Design industrial: bases para a configuração dos produtos industriais. Rio de Janeiro: Edgard Blücher, 2000.

Matéria sobre o potencial das bijuterias. Disponível em: Revista Vogue Brasil junho/2011 Matéria sobre o design de jóia. Disponível Revista Vogue Italia Gioiello- março 2011.

Matéria sobre os acessórios que compõe a moda. Disponível Revista Vogue Italia - Acessory Italy 2008/2009.

MORAES, Dijon de. Limites do design. 2 ed. São Paulo, SP: Studio Nobel, 1999.

SANTAELLA, Lúcia. O que é semiótica. São Paulo: Brasiliense, 2003.

STRICKLAND, Carol. A arte comentada: da pré-história ao pós-moderno. Rio de Janeiro: Ediouro, 1999.

\section{Notas}

\footnotetext{
${ }^{\text {i }}$ Acadêmica do Curso de Design do Centro Universitário Franciscano. (Este texto foi elaborado a partir do Trabalho Final de Graduação "Elementos arquitetônicos do estilo art nouveau como referencial para a criação de uma coleção de jóias" de mesma autoria).
} 